\title{
Partidarismo e ficções jornalísticas: a imprensa na eleição presidencial de 2010
}

\author{
Jakson Ferreira de Alencar
}

\section{Resumo}

0 artigo descreve e analisa a cobertura do jornal Folha de S. Paulo, em associação com outros órgãos de mídia brasileira, na eleição presidencial de 2010. Embora se declare como neutro, objetivo e pluralista, o jornal fez uma evidente, mesmo que não assumida, opção partidária na eleição contra a candidata Dilma Rousseff e a favor de José Serra. Isso aparece na cobertura e nas linhas editoriais subjacentes. A metodologia combina revisão bibliográfica e pesquisa de campo, embasando-se, sobretudo, na teoria sobre a narração dos fatos de Muniz Sodré (2009).

\section{Palavras-chave}

Imprensa. Eleição 2010. Partidarismo.

Folha de S. Paulo. Narração dos fatos.

\section{Jakson Ferreira de Alencar}

jfalencar@yahoo.com.br

Doutorando em Comunicação e Semiótica pela Pontifícia Universidade Católica de São Paulo (PUC-SP).

\section{Introdução}

Apesar do discurso em torno da imparcialidade, objetividade e pluralidade feito pela imprensa, de modo particular pelo jornal aqui abordado como representativo da forma de atuação da imprensa tradicional na eleição de 2010, as críticas à cobertura jornalística na última eleição presidencial foram constantes. A Folha de S. Paulo afirmava que tais críticas seriam desrespeito à liberdade de imprensa ou apenas manifestações partidárias. Entretanto, tais questionamentos partiram não apenas de políticos, mas de vários setores da sociedade interessados na consolidação da democracia, de suas instituições, e na qualificação da imprensa. A Folha, como veremos, tinha uma opção partidária definida e agia em favor de uma candidatura, usando de métodos que, muitas vezes, ao mesmo tempo em que enalteciam princípios éticos e o próprio Manual da Redação, simplesmente os desconsideravam. A opção partidária da imprensa não se restringia a esse jornal, foi quase unânime na imprensa tradicional do país, com poucas exceções, o que comprometeu em muito a qualidade das informações jornalísticas. 
A forte tendência partidária em considerável parte da imprensa do país fez o noticiário deixar de ser informação e tornar-se expressões do chamado wishfull think (expressão de desejos), chegando às raias da ficção.

Dentre os veículos criticados por sua atuação durante a campanha, sobressaíram-se alguns: a rede Globo, a revista Veja e jornais, como Folha de S. Paulo, O Globo e Estado de S. Paulo. Inclusive constatou-se, uma retroalimentação ou uma espécie de "coro" no agendamento de pautas políticas entre esses veículos. Neste artigo, por opção metodológica, delimitamos a abordagem, à imprensa escrita, e, dentro desta, ao jornal Folha de S. Paulo, por ser o de maior tiragem até então. De acordo com o livro de Beatriz Kushnir, Cães de guarda (2004), sobre a atuação do jornal na ditadura, a Folha pode ser definida como "locus privilegiado" para o estudo da atuação da imprensa no período. Pelo que a presente pesquisa levantou a respeito do jornal na campanha de 2010, ele pode também ser definido como locus privilegiado para entender a forma de atuação da imprensa tradicional na eleição de 2010. Este artigo, devido aos limites de espaço, concentra-se no período da campanha eleitoral que vai de três de abril (seis meses antes da eleição) até 25 de agosto.

\section{Objetividade, narração, fatos e factoides no jornalismo}

Na concepção do "espírito positivo" da idade moderna, que marca a humanidade e suas ideias de cognição até hoje, fato é uma experiência sensível da realidade; a cada fato deve corresponder um dado possível, uma sensação, de modo que a intuição empírica torna-se a fonte de todo saber. Vale apenas 0 empiricamente observável. 0 mundo dos fatos é ligado ao "estado de coisas" e os enunciados devem ter correspondência transparente com esse estado de coisas empiricamente comprováveis, com idêntica validade para todos os sujeitos (SODRÉ, 2009, p. 28-31). No senso comum, o significado de fato inclui ocorrências e ações em geral, logo, incluindo o que se sabe sobre 0 caso por observação e experiência, mais que por inferência.

0 jornalismo incorpora esse espírito do positivismo e o senso comum sobre os fatos, cultivando o "mito da neutralidade", a ideia segundo a qual a imprensa, em sua "objetividade", funciona como uma espécie de espelho do real. No mundo científico, após a crítica ao positivismo, sabemos que hoje, mesmo com todo o rigor, a objetividade total não é possível. As críticas feitas pela filosofia e pelas teorias da ciência concluíram pela impossibilidade dos fatos de garantir o necessário rigor ao conhecimento. Com base nisso, há um dito espirituoso corrente, segundo o qual "os jornalistas seriam os últimos positivistas do mundo". Sabemos, no entanto, que a notícia é elaborada em estratégias de construção do acontecimento. 0s fatos podem ser não só transformados pela subjetividade de quem os narra, mas muitas vezes podem conter elementos de ficção ou não passar de factoides criados por razões diversas. 
Na concepção de Sodré (2009), ainda que a ficção literária seja outra coisa, a construção jornalística tem proximidade e produz efeitos (numa escala diferente) análogos àqueles produzidos literariamente. Também a narração jornalística constrói, a partir de regras e convenções discursivas, de hábitos e práticas sociais, um esquema narrativo que transforma a factualidade da vida, envolvendo enredo ou intriga (SODRÉ, 2009, p. 27). Tal construção da narrativa jornalística é atravessada pelas representações das vicissitudes da vida social e pelos conflitos em torno da hegemonia das representações. No enredo da narração jornalística, procurase atribuir coerência espacial e temporal a determinadas manifestações factuais, o que consiste na imitação da realidade, mas com aproveitamento de aspectos da realidade para produzir um discurso que lhe é semelhante ou homólogo (SODRÉ, 2009, p. 37). Na história do Brasil temos diversos exemplos emblemáticos da criação de narrativas jornalísticas. Veremos alguns casos concretos com relação ao período eleitoral de 2010.

\section{A imprensa toma partido}

Um fórum promovido em $1^{0}$ de março de 2010 por um instituto ligado à maior parte dos principais órgãos de mídia do país, que reuniu representantes de tais veículos, serviu para dirimir possíveis dúvidas quanto ao posicionamento políticos desses setores da imprensa na eleição daquele ano. Trata-se do $1^{\circ}$
Fórum Democracia e Liberdade de Expressão 0 qual marcou o encaminhamento da cobertura jornalística na maior parte da imprensa dali por diante. 0 Fórum foi promovido por uma ONG ligada aos principais órgãos de mídia tradicionais do país, chamada Instituto Millenium, que, segundo seu site, não tem vinculação políticopartidária e promove a democracia, a liberdade individual, a propriedade privada e a economia de mercado. (INSTITUTO MILLENIUM, 2010) 0 evento funcionou como uma espécie de contraponto à $1^{\text {a }}$ Conferência Nacional de Comunicação, promovida pelo governo federal em dezembro de 2009 para discutir a comunicação social com representantes da sociedade, dos movimentos sociais, políticos e empresários da área. Estes últimos, no entanto, em grande parte, recusaram-se a participar da conferência, alegando que o governo queria, prejudicar a liberdade de imprensa. Entre os conselheiros do Instituto Millenium presentes no fórum do Instituto Millenium estavam Roberto Civita (editora Abril), Otávio Frias Filho (Folha) e Roberto Irineu Marinho (Globo) e muitos dos principais jornalistas desses veículos. 0 evento contou com o apoio de entidades como a Associação Brasileira de Emissoras de Rádio e Televisão (Abert), Associação Nacional de Editores de Revista (Aner), Associação Nacional de Jornais (ANJ) e Associação Brasileira de Agências de Publicidade (Abap).

A repórter Bia Barbosa acompanhou o evento e fez uma reportagem para a Agência Carta Maior. 
Segundo ela, a explanação inicial foi dada pelo sociólogo Demétrio Magnoli, que, em sua fala, afirmou que o PT é um aparato controlado por sindicalistas e castristas, que têm respondido a suas bases pela retomada e restauração de um programa político remanescente dos antigos partidos comunistas. Outro palestrante, Denis Rosenfield reforçou os argumentos contra as supostas ameaças representadas pelo PT: 0 stalinismo e 0 ataque à liberdade de imprensa $\mathrm{e}$ de expressão (BARB0SA, 2010). 0s debatedores também abordaram 0 que entediam como risco: a eleição de Dilma Rousseff, o que fica claro na seguinte fala de Arnaldo Jabor (apud BARBOSA, 2010), comentarista da Rede Globo, dentre outras:

0 que está na cabeça de quem pode assumir em definitivo o poder no país é um patrimonialismo de Estado. Lula, com seu temperamento conciliador, teve 0 mérito real de manter os bolcheviques e jacobinos fora do poder. Mas conheço a cabeça de comunistas, fui do PC, e isso não muda, é feito pedra. 0 perigo é que a cabeça deste novo patrimonialismo de Estado acha que a sociedade não merece confiança. Se sentem realmente superiores a nós, donos de uma linha justa, com direito de dominar e corrigir a sociedade segundo seus direitos ideológicos. Minha preocupação é que se o próximo governo for da Dilma, será uma infiltração infinita de formigas neste país. Quem vai mandar no país é o Zé Dirceu e o Vaccarezza. A questão é como impedir politicamente o pensamento de uma velha esquerda que não deveria mais existir no mundo.

Embora o Instituto Millenium ressalte em seu site que não possui ligações político-partidárias, os debates do Fórum revelaram um partidarismo radical, como se pode ver nesta declaração de
Jabor e na seguinte, de Demétrio Magnoli (apud BARBOSA, 2010): "Se o Serra ganhasse, faríamos uma festa em termos das liberdades. Seria ruim para os fumantes, mas mudaria muito em relação à liberdade de expressão. Mas a perspectiva é que a Dilma vença”. Jabor defende que a imprensa assuma atitudes agressivas na campanha para evitar os anunciados "riscos": "Então o perigo maior que nos ronda é ficar abstratos enquanto os outros são objetivos e obstinados, furando nossa resistência. A classe, o grupo e as pessoas ligadas à imprensa têm que ter uma atitude ofensiva e não defensiva." (BARBOSA, 2010). Reinaldo Azevedo (apud BARBOSA, 2010), colunista da revista Veja, completou: "Na hora em que a imprensa decidir e passar a defender os valores que são da democracia, da economia de mercado e do individualismo, e que não se vai dar trela para quem quer a solapar, começaremos a mudar uma certa cultura".

Uma declaração da presidente da ANJ e superintendente da Folha ao jornal $O$ Globo, anterior ainda ao fórum, já não deixava dúvida quanto à cobertura partidarizada da imprensa tradicional:

A liberdade de imprensa é um bem maior que não deve ser limitado. A esse direito geral, o contraponto é sempre a questão da responsabilidade dos meios de comunicação. E, obviamente, esses meios de comunicação estão fazendo de fato a posição oposicionista deste país, já que a oposição está profundamente fragilizada (AZENHA, 2010).

Tal declaração foi dada no contexto das críticas que a imprensa fazia ao terceiro Plano Nacional 
de Direitos Humanos que, no entender deles, ameaçava a liberdade de imprensa. Coincidência ou não, após o fórum, $o$ tom e a intensidade do noticiário, contrários ao governo e à sua candidata, subiram, como veremos adiante, com poucas diferenças entre os principais veículos que participaram do encontro.

Embora no fórum tenham sido expostas as opções políticas de boa parte da imprensa ali representada, jamais houve declaração em editoriais da quase totalidade deles informando os leitores sobre opção por alguma candidatura. 0 discurso da imparcialidade foi mantido, enquanto as pautas e as informações eram totalmente contaminadas pela opção partidária.

\section{Panorama da cobertura da Folha entre abril e final de agosto de $\mathbf{2 0 1 0}$}

Nesse período, a Folha levantou uma série de temas negativos para a candidatura de Dilma, 0 governo federal e 0 Partido dos Trabalhadores, $\mathrm{e}$ temas positivos para Serra "às vezes, os textos parecem releases da campanha deste, como veremos a seguir", dosando com alguns temas negativos, de menor relevância ou com espaço e visibilidade reduzidos, para Serra, e raros temas positivos para Dilma, sempre acompanhados de viés ou contraponto negativo.

\subsection{0 esforço para "ressuscitar" escândalos passados}

Uma das estratégias do jornal, que, como veremos correspondia ao discurso de membros do PSDB no período, foi a rememoração dos escândalos que a imprensa e a oposição denominaram "mensalão" e "aloprados". ${ }^{1}$ Em 4 de abril, o jornal publicou matéria com 0 título Campanha de Dilma não dá espaço para o PT de raiz (p. A10). No conteúdo da matéria, o jornal afirma que, no núcleo da campanha de Dilma, não há membros do PT de quando o mesmo foi fundado, na década de 1980, pois teriam sido abatidos pelos escândalos de corrupção do governo. Ao lado e, com o mesmo espaço, o que dá a entender imparcialidade, outra matéria: Serra chama o mesmo grupo que o ajudou quatro anos atrás, ou seja, fica subentendido que, no caso de Serra, ele pode chamar o grupo do passado, pois no PSDB ninguém teria sido abatido por escândalos. Entretanto, "quatro anos atrás" é diferente de "30 anos atrás" (1980). Embora pareçam equivalentes, as matérias não o são, pois não mencionam correligionários de Serra de mais de quatro anos atrás. Por exemplo, não são citados membros do PSDB envolvidos em escândalos ocorridos no governo de Fernando Henrique Cardoso.

Este caso consiste no escândalo do suposto dossiê contra tucanos da eleição de 2006, que, desencadeado 15 dias antes do primeiro turno daquela eleição presidencial, tornou-se praticamente o tema único na mídia de maior abrangência no período que antecedeu a votação. 0 caso foi estudado na tese de doutorado de Florentina Souza (2007). A autora demonstra como 0 caso e a forma maciça como foi trabalhado pela mídia foram importantes para levar aquela eleição para o segundo turno. 
No dia seguinte, 0 tema foi o caso dos "aloprados" da eleição de 2006: Juiz diz que 'aloprado' levou mala de dinheiro (p. A4). 0 inquérito sobre 0 caso está em andamento, mas havia sido esquecido após o fechamento das urnas da eleição de 2006, sinal de que 0 interesse sobre 0 caso restringia-se a influenciar a eleição, e as tentativas de relembrálo, às vésperas de nova eleição, seguiam na mesma direção. Em 6 de abril, o tema aparece novamente no jornal, em espaço nobre: Vamos ressuscitar os aloprados', diz tucano (p. A6). Tratava-se de uma frase do presidente nacional do PSDB, o então senador Sérgio Guerra, que virou manchete no jornal. A matéria parece release do comitê de Serra. Temas novos foram surgindo ou sendo criados, mas as temáticas "mensalão" e "aloprados" foram sempre aparecendo, seja em entrevistas, seja em infográficos e quadros rememorativos.

Observa-se que há uma unidade entre os conteúdos do jornal e as falas de correligionários de José Serra. Na edição dominical de 6 de junho, duas páginas são concedidas a uma rememoração do "mensalão", com direito a infográfico que relembra em seis tópicos os principais fatos desse caso, sob o título MENSALÃO - o que foi o maior escândalo de corrupção do governo Lula (p. A4), e na página A8 da mesma edição, título em letras garrafais, de forma diferenciada dos títulos comuns do jornal: Por onde andam. 0 título fica em meio a um círculo com grandes fotos dos principais envolvidos no caso, das quais partem setas para seus nomes, resumos biográficos e das acusações recebidas durante 0 escândalo. Em
25 de agosto, 0 título de uma matéria alardeava o conteúdo do programa de televisão de José Serra: No horário eleitoral, Serra liga Dilma ao mensalão e a Dirceu (p. A 11); o subtítulo completava: "Olha quem tá querendo voltar', diz locutor ao exibir a imagem do ex-ministro ao lado da candidata petista".

\section{2 "Divisões" versus "uniões"}

Enquanto retomava escândalos da agenda da última eleição, a Folha focava outro assunto que também não era novo, mas que foi sendo relembrado: o PT seria um partido dividido e que provocaria divisões; a base aliada do governo teria rachas e divisões. A manchete principal da capa do domingo, 11 de abril, foi a seguinte: Serra critica PT por dividir o país e defende o diálogo - pré-candidato do PSDB condena 'falange do ódio' e a falsa disputa entre Norte e Sul e pobres e ricos. Muitas vezes, declarações de Serra e aliados viraram manchete dessa forma na Folha, durante a campanha. Abaixo dessa manchete e da chamada de capa, uma foto de Serra com braços abertos, discursando, e a legenda: "REVOADA TUCANA - José Serra no lançamento da pré-candidatura a presidente pelo PSDB; em entrevista exclusiva, o ex-governador defende 0 desenvolvimento industrial e 'ativismo estatal". Na parte interna do primeiro caderno, outra manchete em mesmo tom: "Serra acusa PT de dividir o país e cultuar impunidade". No texto, o candidato chama os opositores de "falange do ódio". Uma matéria menor, abaixo, exalta 0 
que para o jornal foi o sucesso do lançamento da pré-candidatura do PSDB: "Calor, lotação, musas e tecnologia marcam evento". 0 conteúdo da matéria diz que o lançamento teve o dobro do público esperado. Na mesma edição, ainda: "Aécio afirma que estará 'ao lado' de Serra" e uma "análise": "Tucanos largam unidos". 0 jornal enaltece a suposta "união" dos tucanos, não obstante o país tenha assistido a uma disputa ferrenha entre Aécio e Serra pela vaga para candidatura presidencial pelo partido.

Para o jornal o PT estava sempre dividido e promovendo divisões, embora o partido demonstrasse maior coesão interna em torno da candidatura de Dilma que 0 PSDB em relação à candidatura de Serra. Em contraste com esse fato, as manchetes e matérias sobre as "divisões", "rachas" e "divergências" na candidatura de Dilma e entre seus aliados foram frequentes, buscando-se sempre qualquer elemento que pudesse servir de gancho para matérias com esse tema, seja na candidatura central seja em candidaturas a governador nos estados. Em 3 de abril: Equipe de Dilma diverge sobre roteiro de pré-campanha (p. A8); em 15 de abril: Dilma discute com base problemas regionais (p. A9); em 23 de abril: Com problemas entre PT $e$ PDT no Paraná, Dilma cancela viagem (p. A7); em 15 de maio: Crise com Jader abala aliança do PT no Pará (p. A9); em 2 de maio: Dividido, PT-MG faz prévia para o governo (p. A9); em 16 de maio: PT e PMDB travam guerra judicial na Bahia (p. A10). São apenas alguns exemplos dos destaques dados às divergências entre PT e aliados.
As dificuldades desse gênero entre os tucanos, como se soube, principalmente por outros canais, a blogosfera em particular, tinham maiores proporções em diversos estados, mas pouco apareceram nas páginas do jornal e da imprensa similar. Apenas para citar um dos exemplos, no estado do Paraná, houve divisão entre Beto Richa e seu grupo e Álvaro Dias. Richa foi candidato e Dias não o apoiou, preferindo apoiar seu adversário, que era aliado ao PT, Osmar Dias. A divisão maior se deu em relação à escolha do vice de José Serra, com muitos indicados que não aceitavam a função. Foi um processo cheio de idas e vindas. Sendo que o candidato acabou por definir um vice de seu próprio partido, Álvaro Dias. 0 anúncio foi destaque em toda a imprensa. Nos dias seguintes, sob protestos do partido Democratas (DEM), que exigia a vaga de vice para coligar-se ao PSDB, houve uma troca, optandose pelo demista Índio da Costa. Sobre assunto a Folha ocultava fatos, publicava matérias otimistas e que amenizavam as dificuldades. Por exemplo, em 29 de outubro, o jornal novamente utiliza uma frase de Serra como manchete: Crise do vice será resolvida, afirma Serra, com o subtítulo: "Não se preocupem', diz tucano a jornalistas após reiterar que 'algumas dificuldades' são normais em política" (p. A4). É óbvia a diferença de tratamento dessa ordem de problemas nas matérias que se referiam à candidatura do PT e nas relativas ao PSDB. A largada unida da candidatura tucana e as divisões do outro lado conforme publicadas no jornal estiveram repletas de elementos de ficção jornalística. 


\section{3 "Tropeços" versus "acertos"}

Nos meses iniciais da pré-campanha até as convenções, em junho, Dilma havia subido nas pesquisas e se aproximado dos números de Serra. Nesse período, além dos temas já apontados acima, o jornal teve como tônica aquilo que chamou de "erros" de Dilma na campanha, suas supostas dificuldades, segundo o jornal, de adquirir postura de candidata, de empolgar, de fazer corpo a corpo, falta de carisma, o que certamente, segundo a Folha, dificultaria muito que decolasse. Serra, ao contrário, era mostrado como bom gestor e líder de uma campanha bemsucedida. Em 8 de abril, uma matéria declarava que Dilma ainda sofre para agir como candidata e enfrentar o corpo a corpo (p. A4). A foto, no entanto, contrastava com tal informação: a candidata aparece sorridente, rodeada de pessoas a quem cumprimentava.

Em 26 de abril, uma chamada na capa sobre a participação de Dilma em entrevistas na televisão afirma que Lula chama Dilma e se queixa de seu desempenho na TV (p. A4). No interior do primeiro caderno, outro título diz que "assessores da pré-candidata consideram que, nesta fase da campanha, José Serra está se saindo melhor e demonstrando experiência". No conteúdo da matéria: "nas palavras de um aliado da ministra, que não quis ser identificado, 'a experiência de Serra em campanhas está fazendo a diferença, ele está deixando a impressão de que é mais experiente, falando serenamente, fazendo uma campanha mais governista do que Dilma". 0 trecho seguinte resume boa parte do que se falava de Dilma no jornal e na maior parte da imprensa nesse período: "Do outro lado, a petista tem se desgastado mais, entrado em mais polêmicas, batendo demais na tecla da comparação entre os governos FHC e Lula e deixado em segundo plano a apresentação de propostas que possam entusiasmar 0 eleitor".

As fontes citadas para informar o conteúdo da suposta conversa reservada entre 0 então presidente e sua candidata foram os genéricos "assessores" e "aliado que não quis se identificar", nenhum nome é citado. É estranho e pouco confiável informações de relevância sobre conversas privadas de figuras dessa importância em uma campanha sem que a fonte real seja citada. É ainda mais estranho que um assessor que prive da intimidade de um presidente e de sua candidata dê declarações à imprensa que a hostilizava que mais parecem um release da candidatura adversária. Alguns trechos parecem muito diferentes do que diria um assessor de campanha e a construção da frase tem um tom bastante artificial, caindo como uma luva para a linha editorial do jornal e tudo o que o mesmo afirmava sobre a candidata. Outros trechos dessa mesma matéria (26 de abril, p. A4), como o que fala das dificuldades de Dilma, parecem um artigo ou editorial, e não uma matéria informativa, por exemplo, quando afirma que Serra está fazendo a diferença, deixando a impressão de que tem mais experiência, o que são impressões subjetivas 
não assentadas em dados concretos. Uma das características do noticiário político do jornal na campanha foi esse abuso do recurso a supostas declarações dadas em off.

O tema dos supostos "tropeços" de Dilma continuou recorrente. Em 13 de junho, o jornal publicou uma página inteira sobre Dilma, na qual a maior parte é ocupada por uma caricatura em que ela usa um secador de cabelos (p. A6). Abaixo, fotos da candidata com diversos cabelos diferentes, desde que começaram a crescer após as sessões de quimioterapia a que teve de submeter-se. A exposição dessas imagens, não por acaso, aludem ao que a oposição, com apoio de setores da imprensa, no período, falavam sobre Dilma Rousseff: a candidata teria muitas caras. No título, em letras garrafais: Dilma Rousseff (PT) DEBATER OU NÃO DEBATER, no qual esse último trecho aparece em tamanho bem maior, sugerindo uma suposta indecisão da então ministra em participar ou não de debates. Uma das teses dos tucanos e de quem os apoiava nesse período, a maior parte da imprensa tradicional inclusive, era de que, quando iniciassem os debates, Serra se sairia muito melhor e abriria vantagem nas pesquisas, por ser, segundo tais setores, mais preparado para debates.

0 tema do suposto despreparo e da falta de experiência continuou rendendo até 0 fim da campanha, somando-se a um suposto passado que, segundo matéria de 10 de agosto, Dilma gostaria de esquecer: Cineasta diz que Dilma tenta ocultar seu passado (p. A7). 0 cineasta que ganhou página de destaque no primeiro caderno do jornal com 0 recorrente tema da acusação de que Dilma teria participado da resistência armada à ditadura foi Fernando Meirelles, que atuou na campanha de Marina Silva. Um dos trechos mais polêmicos da fala dele foi posto como "olho" (destaque) da matéria, em negrito e letras maiores: "Não sei se existe uma biografia da Dilma [Rousseff], mas como ela tem passado de guerrilha, que $90 \%$ da população não sabe, no caso dela não seria oportuno. Ela iria omitir uma parte". A matéria tem como gancho o lançamento de uma biografia de Marina Silva. Em outro trecho, entre aspas, Meirelles completa: "Talvez fosse melhor para ela ficar quietinha. Não fazer biografia, não ir aos debates. Quanto menos exposição, melhor". A matéria não concede espaço a alguém que faça contraponto, não há "outro lado". Bem como o único "cineasta" que ganhou esse espaço no jornal foi alguém com opinião específica sobre a guerrilha, alinhada com o posicionamento do jornal sobre o tema manifestado em várias matérias do período. Não aparece opinião de nenhum outro "cineasta" que pense diferente.

A temática da "inexperiência" e da "falta de preparo para debates" foi arrefecendo após 0 primeiro debate realizado na rede Band de televisão em 5 de agosto, no qual o desempenho dos candidatos foi equilibrado, segundo a avaliação de suas próprias assessorias, confirmadas por avaliações feitas em órgãos de 
imprensa de diferentes tendências (MACHADO, 2011). Entretanto, o jornal continuava endossando a tese de que o candidato do PSDB seria mais experiente que sua adversária. Em 7 de agosto, uma matéria intitulada Serra vai intensificar comparações entre históricos com Dilma explorava o que, segundo o candidato e o jornal, seria um histórico muito superior de José Serra.

No mesmo dia, o jornal concede duas páginas de entrevista a José Serra, na qual 0 apoio à sua candidatura fica evidente. Os título e subtítulo dão o tom da entrevista: A pior coisa é você parecer o que não é; tenho uma cara só - Tucano diz ter 'conteúdo popular', mas admite que não é conhecido pela origem humilde; na segunda candidatura, diz estar mais preparado para presidir o país (p. A14-A15). Além de uma foto que toma dois terços de uma das páginas com um José Serra sorridente e outras várias retratando a biografia do candidato em forma semelhante ao que se faz nos programas eleitorais, as perguntas da entrevista são benevolentes e não há nenhuma pergunta espinhosa ou relativa a problemas no governo de São Paulo, como poderia ser o caso Alstom, ${ }^{2}$ por exemplo. Em geral, são perguntas que "levantam a bola para o candidato cortar". Citamos alguns exemplos: "O Sr. era presidente da UNE [União Nacional dos Estudantes] em
1964, quando houve o golpe militar, e foi exilado, mas não participou da luta armada [grifo nosso]. Por que?"; ; "0 senhor se definiria como desenvolvimentista?"; "0 senhor vai pregar na campanha o Estado ativo. 0 que significa?".

\subsection{Matérias jornalísticas se confundem com releases de campanha}

Muitas matérias publicadas nesse período também parecem releases do governo estadual de São Paulo ou da campanha de José Serra. Em 25 de maio, uma chamada de capa, com direito a foto ocupando dois terços da parte de cima da capa, traz o título Metrô do futuro. 0 texto da chamada e 0 conteúdo da matéria (p. C3) abordam as obras e os planos de conclusão do metrô até 2014 feitos pelo governo do estado de São Paulo, como fatos consumados. As promessas de campanha neste caso, e em muitos outros não citados aqui, viraram notícias factíveis. 0 tom é de louvor: "0 plano do governo do estado de São Paulo é expandir a rede de metrô e trem para $520 \mathrm{~km}$ até 2014 , ano da Copa do Mundo, $59 \%$ mais que os $327 \mathrm{~km}$ atuais. 0 custo de contratos já firmados soma R $\$ 23$ bilhões”. Após a posse de Geraldo Alckmin no governo do Estado, em 2010, sua equipe anunciou: do que fora divulgado nas propagandas, 0 andamento das obras e 0 orçamento do Estado

Acusações referentes a propinas em contratos do governo do estado com a empresa transnacional Alstom para a compra de trens para o metrô.

30 tema da luta armada e da suposta participação de Dilma nela foi uma obsessão do jornal durante a campanha, sendo que meses antes, em 5 de abril de 2009, o jornal publicou uma ficha falsa da candidata, ligando-a à luta armada e a diversos "crimes" não cometidos por ela, mas que constavam na ficha, apresentada com destaque na capa e em três páginas no primeiro caderno. 
permitiriam concluir até 2014 apenas o relativo à linha amarela, as demais ficariam para o futuro, sem definição precisa de prazos.

Já com relação a obras e planos do governo federal 0 tratamento era bem diferente. Em 8 de abril, uma matéria intitulada Serra analisa dados do PAC [Programa de Aceleração do Crescimento] para discurso de pré-candidatura (A7), aborda "nós" e "problemas" do programa apontados pelo tucano. 0 programa do governo federal foi frequentemente noticiado com relação a atraso em obras, problemas ambientais, suspeitas de desvios ou mesmo como um programa inexistente. Pouco se sabe, por meio do jornal, a respeito das obras, de suas inaugurações ou possíveis benefícios para a população. Já com relação ao governo Serra, a cobertura jornalística é bem diferente. No resumo em negrito, no início da mesma matéria, o jornal afirma que "ex-governador quer mostrar 'linhas de ação' e exaltar resultados obtidos por seu governo para destacar sua capacidade de investimento".

\subsection{Em busca de novos escândalos}

0 assunto do dossiê contra tucanos que, posteriormente, será a intensa pauta do jornal e da maior parte da imprensa entre 26 de agosto e 11 de setembro, já era tema da Folha no mês de junho. No dia 4, a manchete da capa informava: PT interpela Serra na justiça, e o subtítulo: "partido quer que tucano confirme declaração que culpa Dilma por dossiê; para PSDB, 'querem transformar vítima em réu'" (p. A4). Os tucanos levantam 0 tema do dossiê, acusando o PT, mas se dizem vítimas do que eles próprios difundiam, embora sem abordar qual seria o conteúdo do suposto dossiê. Em 12 de junho, manchete de capa em letras garrafais afirma: "Dossiê do PT traz dados fiscais sigilosos de dirigente tucano - equipe de pré-campanha de Dilma investigou Eduardo Jorge; presidente petista nega envolvimento do partido" (p. A4). Não havia provas de que o dossiê fosse feito pelo PT. Após as investigações da Polícia Federal a respeito, descobriu-se que a criação do dossiê teve outro caminho, e a venda de dados da receita por parte de funcionários não dependia de partidos. Foram quebrados sigilos de pessoas de diversos partidos, inclusive do próprio PT. No dia seguinte, 13 de junho, uma chamada de capa divulgava que Para tucanos, PT cometeu crime ao montar dossiê.

Percebe-se que, nas páginas da Folha, o que pudesse ser arrolado como tema negativo para a candidata do PT, mesmo que fosse assunto irrelevante, ganhava espaço. Os números citados pela candidata, por exemplo, eram sempre checados e, sempre que havia brecha, teciase uma crítica ou um desmentido, mesmo que recorrendo àquilo mesmo de que se acusava a candidata: distorções de números. 0s outros candidatos, José Serra em particular e seu governo, não tiveram um acompanhamento crítico do jornal nesses moldes.

0 jornal consegue transformar em notícia negativa até mesmo as visitas de Dilma a templos 
religiosos. Em matéria de 15 de maio: Mães de santo abençoam católica Dilma e no subtítulo: "presidenciável do PT vai a uma missa pela manhã e ao dia de 0xalá, à noite" (p. A6). Para 0 jornal, por ser católica, ela deveria visitar apenas templos de sua religião. 0 trecho em negrito, abaixo do subtítulo, já trazia a questão do aborto, que depois viraria tema mais forte, às vésperas do primeiro turno: "Questionada sobre 0 aborto, pré-candidata ao Planalto diz que 'mulher nenhuma é a favor do aborto', mas que o Estado tem de cumprir a lei”. Já com relação à ortodoxia religiosa de José Serra, o jornal não tinha dúvida: Padre Marcelo pede prece para Serra (4 jun. 2010, p. A7). Supõe-se que, em um Estado que se pretende laico não há necessidade de que candidatos a cargos públicos forneçam atestados a respeito de sua pertença religiosa, como as matérias dão a entender.

0 noticiário negativo em relação ao governo federal e à sua candidata contou com inúmeras outras manchetes de capa e matérias, das quais elencamos algumas, a seguir. No domingo, 2 de maio, a manchete principal da capa destacou que a PF vêfraude bilionária na Petrobras; 0 subtítulo afirmava que "acerto de empreiteiras elevou custo em $R \$ 1,4$ bi; estatal e empresa negam". Segundo a chamada e a matéria que ocupou a página A4, "Ao menos 5 obras da Petrobras licitadas no governo Lula foram alvos de acordos e manobras clandestinas de empreiteiras que resultaram, de acordo com a Polícia Federal, em custo adicional".
A página seguinte, A5, é inteiramente ocupada por um anúncio e, apenas na página subsequente, A6, abaixo de coluna com outro tema, o jornal publica um "outro lado" a respeito da matéria sobre a Petrobras: "Estatal nega superfaturamento das obras". A estatal informou que a diferença de valores se deu pela disparidade entre os parâmetros técnicos usados pelo Tribunal de Contas da União e a PF e os adotados pelo corpo de engenheiros da companhia. 0 Tribunal de Contas da União (TCU) e a PF se pautaram, segundo a empresa, pelo Sistema Nacional de Pesquisa de Custos e Índices da Construção Civil (Sinapi), empregado em obras de saneamento e habitação, e pelo Sistema de Custos Rodoviários (Sicro), usado pelo Departamento Nacional de Infraestrutura de Transportes (Dnit), com relação à construção de estradas. A Petrobras "considera que esses critérios não se aplicam a obras como uma refinaria de petróleo, mais complexa e com especificidades próprias". A nota também informa que, com relação a uma das obras envolvidas na matéria, a Unidade de Tratamento de Gás de Caraguatatuba, o TCU já reavaliou e atestou que não houve sobrepreço. 0 "outro lado" foi ocultado, em contraste com a manchete de capa e a matéria, que carimbam o governo e a estatal como corruptos. Já sobre suspeitas com indícios graves que havia contra a atuação de José ou de correligionários seus seja no governo e prefeitura de São Paulo a população não teve o direito de ficar sabendo pelos jornais e revistas de grande circulação e os telejornais de maior audiência. Apenas canais alternativos, como a blogosfera 
e revistas de circulação menor, como a Carta Capital, noticiaram e fizeram investigações jornalísticas a respeito.

\section{Conclusão}

A opção partidária por parte de um órgão de imprensa em si não é ilegítima; entretanto, é honesto para com os leitores e para com a população em geral, nos casos em que há uma opção, que se declare em editoriais, como é feito em muitos países. Aqui no Brasil, isso geralmente é feito apenas pela revista Carta Capital no início das campanhas. Em tais situações, ao mesmo tempo em que se declara 0 apoio, procurase restringi-lo a editoriais e textos opinativos, separando ao máximo as opções partidárias das informações, embora, como vimos, toda narração de fatos implique subjetividades e haja uma variada gama de forças agindo sobre a produção das notícias. No caso da Folha quanto à sua atuação na eleição de 2010, além de não ter havido a declaração da preferência partidária, procurava-se camuflá-la e, o que é mais problemático, não houve separação entre apoio partidário e informação. 0 jornal, em variadas ocasiões, manifestou não apenas 0 seu partidarismo, mas um partidarismo militante que parecia não importar-se com a credibilidade do jornal. A cobertura da Folha, em coro com muitos outros veículos, repercutindo-os ou sendo repercutida por eles, misturou frequentemente fatos com opiniões e boatos, somando-se a isso outros elementos como torcida; manifestações de desejos travestidas de informação; argumentação frágil e com pouca lógica; estratégias óbvias e já desgastadas pelo uso repetitivo em diversas eleições; incapacidade de fundo de analisar processos econômico-sociais para construir posicionamentos e críticas com um mínimo de sofisticação; teses e hipóteses furadas; narrativas e entrevistas enviesadas; fontes e offs de baixa credibilidade. Muitas estratégias e narrativas tinham o nível do anticomunismo dos anos 60 a 80, e assumiam o caráter de cruzada contra os "perigos" que rondariam essa órbita.

\section{Referências}

AZEVED0, Antônio. Mídia e democracia no Brasil: relações entre 0 sistema de mídia e 0 sistema político. Opinião Pública. Campinas, ano 12, n. 1, p. 88-113, abr./ maio 2006.

BARBOSA, Bia. Grande mídia organiza campanha contra candidatura de Dilma.

Carta Maior. São Paulo, abr. 2010. Disponível em: < http://www.cartamaior.com.br/templates/ materiaMostrar.cfm?materia id =16414 > Acesso em: 18 abr. 2010.

FOLHA DE S. PAULO. Manual da redação. São Paulo: Publifolha, 2001.

FOLHA DE S. PAULO. [Toda a cobertura política nos meses de abril a novembro de 2010]. São Paulo, 2010. INSTITUTO MILLENIUM. São Paulo, 2010. Quem somos. Disponível em: < http://www.imil.org.br/ institucional/quem-somos/>. Acesso em: 20 mar. 2010.

KUSHNIR, Beatriz. Cães de guarda: jornalista e censores do AI-5 à constituição de 1988. São Paulo: Boitempo, 2004.

LIMA, Venicio A. de. A mídia nas eleições de 2006. São Paulo: Perseu Abramo, 2007. 
MACHADO, Maria Berenice da Costa. Debates nas campanhas presidenciais: Brasil 1989-2010. In: ENCONTRO NACIONAL DE HISTÓRIA DA MÍDIA, 8., 2011. Guarapuava. Anais... Guarapuava, 2011.

SODRÉ, Muniz. A narração do fato. Petrópolis, RJ: Vozes, 2009.

SODRÉ, Muniz. Espaço público brasileiro. Luis Nassif OnLine. São Paulo, 2010. Disponível em: $<\underline{\text { http: } / /}$ www.advivo.com.br/blog/luisnassif/o-espaco-publicobrasileiro-por-muniz-sodre > . Acesso em: 29 set. 2010 SOUZA, Florentina das N. 0 Jornal Nacional e as eleições presidenciais 2002-2006. 2007. Tese (Doutorado em Comunicação) - Escola de Comunicação e Artes, Universidade de São Paulo, São Paulo, 2007.

WOLF, Mauro. Teorias da Comunicação. São Paulo: Martins Fontes, 2003. 


\section{Partisanship and journalistic fictions: the press in the $\mathbf{2 0 1 0}$ Presidential election}

\section{Partidarismo y ficciónes} periodísticas: la prensa en la elección presidencial de 2010

\section{Resumen}

El artículo describe y analiza la cobertura del diario Folha de S. Paulo, em asociación con otros media brasileños em la elección presidencial de 2010. Aunque se declare como neutro, objetivo y pluralista, el diario há hecho uma evidente, aun que no assumida, opición partidaria en la elección, contra la candidata Dilma Rousseff y a favor del candidato José Serra, lo que aparece en la cobertura periodista y em las líneas editoriales subyacentes. La metodología combina revisión bibliográfica y pesquisa de campo, embasándose, principalmente, en la teoría sobre la narración de los hechos de Muniz Sodré (2009).

\section{Palabras-clave}

Prensa. Elección 2010. Partidarismo. Folha de S. Paulo. Narracción de los fatos. 


\section{Expediente}

A revista E-Compós é a publicação científica em formato eletrônico da Associação Nacional dos Programas de Pós-Graduação em Comunicação (Compós). Lançada em 2004, tem como principal finalidade difundir a produção acadêmica de pesquisadores da área de Comunicação, inseridos em instituições do Brasil e do exterior.

\section{E-COMPÓS I www.e-compos.org.br I E-ISSN 1808-2599}

Revista da Associação Nacional dos Programas

de Pós-Graduação em Comunicacão.

Brasília, v.16, n.2, maio/ago. 2013

A identificação das edições, a partir de 2008

passa a ser volume anual com três números.

\section{CONSELHO EDITORIAL}

Afonso Albuquerque, Universidade Federal Fluminense, Brasil Alberto Carlos Augusto Klein, Universidade Estadual de Londrina, Brasil Alex Fernando Teixeira Primo, Universidade Federal do Rio Grande do Sul, Brasil Ana Carolina Damboriarena Escosteguy, Pontifícia Universidade Católica do Rio Grande do Sul, Brasi

Ana Gruszynski, Universidade Federal do Rio Grande do Sul, Brasil Ana Silvia Lopes Davi Médola, Universidade Estadual Paulista, Brasil André Luiz Martins Lemos, Universidade Federal da Bahia, Brasil Ângela Freire Prysthon, Universidade Federal de Pernambuco, Brasil Antônio Fausto Neto, Universidade do Vale do Rio dos Sinos, Brasil Antonio Carlos Hohlfeldt, Pontifícia Universidade Católica do Rio Grande do Sul, Brasil Antonio Roberto Chiachiri Filho, Faculdade Cásper Líbero, Brasil Arlindo Ribeiro Machado, Universidade de São Paulo, Brasil Arthur Autran Franco de Sá Neto, Universidade Federal de São Carlos, Brasil Benjamim Picado, Universidade Federal Fluminense, Brasil

César Geraldo Guimarães, Universidade Federal de Minas Gerais, Brasil Cristiane Freitas Gutfreind, Pontifícia Universidade Católica do Rio Grande do Sul, Brasil Denilson Lopes, Universidade Federal do Rio de Janeiro, Brasi Denize Correa Araujo, Universidade Tuiuti do Paraná, Brasil Edilson Cazeloto, Universidade Paulista , Brasi Eduardo Peñuela Cañizal, Universidade Paulista, Brasil Eduardo Vicente, Universidade de São Paulo, Brasil Eneus Trindade, Universidade de São Paulo, Brasi Erick Felinto de Oliveira, Universidade do Estado do Rio de Janeiro, Brasi Florence Dravet, Universidade Católica de Brasilia, Brasil Francisco Eduardo Menezes Martins, Universidade Tuiuti do Paraná, Brasil Gelson Santana, Universidade Anhembi/Morumbi, Brasil Gilson Vieira Monteiro, Universidade Federal do Amazonas, Brasil Gislene da Silva, Universidade Federal de Santa Catarina, Brasil Guillermo Orozco Gómez, Universidad de Guadalajara

Gustavo Daudt Fischer, Universidade do Vale do Rio dos Sinos, Brasil Hector Ospina, Universidad de Manizales, Colômbia

Herom Vargas, Universidade Municipal de São Caetano do Sul, Brasi leda Tucherman, Universidade Federal do Rio de Janeiro, Brasil Inês Vitorino, Universidade Federal do Ceará, Brasil Janice Caiafa, Universidade Federal do Rio de Janeiro, Brasil Jay David Bolter, Georgia Institute of Technology Jeder Silveira Janotti Junior, Universidade Federal de Pernambuco, Brasil João Freire Filho, Universidade Federal do Rio de Janeiro, Brasil John DH Downing, University of Texas at Austin, Estados Unidos
José Afonso da Silva Junior, Universidade Federal de Pernambuco, Brasi José Carlos Rodrigues, Pontifícia Universidade Católica do Rio de Janeiro, Brasi José Luiz Aidar Prado, Pontifícia Universidade Católica de São Paulo, Brasil José Luiz Warren Jardim Gomes Braga, Universidade do Vale do Rio dos Sinos, Brasil Juremir Machado da Silva, Pontifícia Universidade Católica do Rio Grande do Sul, Brasil Laan Mendes Barros, Universidade Metodista de São Paulo, Brasil Lance Strate, Fordham University, USA, Estados Unidos Lorraine Leu, University of Bristol, Grã-Bretanha Lucia Leão, Pontifícia Universidade Católica de São Paulo, Brasil Luciana Panke, Universidade Federal do Paraná, Brasil Luiz Claudio Martino, Universidade de Brasília, Brasil Malena Segura Contrera, Universidade Paulista, Brasil Márcio de Vasconcellos Serelle, Pontifícia Universidade Católica de Minas Gerais, Brasil Maria Aparecida Baccega, Universidade de São Paulo e Escola Superior de Propaganda e Marketing, Brasil

Maria das Graças Pinto Coelho, Universidade Federal do Rio Grande do Norte, Brasil Maria Immacolata Vassallo de Lopes, Universidade de São Paulo, Brasil Maria Luiza Martins de Mendonça, Universidade Federal de Goiás, Brasi Mauro de Souza Ventura, Universidade Estadual Paulista, Brasil

Mauro Pereira Porto, Tulane University, Estados Unidos Nilda Aparecida Jacks, Universidade Federal do Rio Grande do Sul, Brasi Paulo Roberto Gibaldi Vaz, Universidade Federal do Rio de Janeiro, Brasi Potiguara Mendes Silveira Jr, Universidade Federal de Juiz de Fora, Brasi Renato Cordeiro Gomes, Pontifícia Universidade Católica do Rio de Janeiro, Brasil Robert K Logan, University of Toronto, Canadá

Ronaldo George Helal, Universidade do Estado do Rio de Janeiro, Brasil Rosana de Lima Soares, Universidade de São Paulo, Brasi Rose Melo Rocha, Escola Superior de Propaganda e Marketing, Brasil Rossana Reguillo, Instituto de Estudos Superiores do Ocidente, Mexico Rousiley Celi Moreira Maia, Universidade Federal de Minas Gerais, Brasi Sebastião Carlos de Morais Squirra, Universidade Metodista de São Paulo, Brasil Sebastião Guilherme Albano da Costa, Universidade Federal do Rio Grande do Norte, Brasil

Simone Maria Andrade Pereira de Sá, Universidade Federal Fluminense, Brasi Tiago Quiroga Fausto Neto, Universidade de Brasília, Brasil Suzete Venturelli, Universidade de Brasília, Brasil Valério Cruz Brittos, Universidade do Vale do Rio dos Sinos, Brasil Valerio Fuenzalida Fernández, Puc-Chile, Chile

Veneza Mayora Ronsini, Universidade Federal de Santa Maria, Brasi Vera Regina Veiga França, Universidade Federal de Minas Gerais, Brasil

\section{COMISSÃO EDITORIAL}

Adriana Braga I Pontifícia Universidade Católica do Rio de Janeiro, Brasi

Felipe Costa Trotta I Universidade Federal Fluminense, Brasi CONSULTORES AD HOC

Alexandre Barbalho, Universidade Estadual do Ceará, Brasil

Ana Carolina Escosteguy, Pontifícia Universidade Católica do Rio Grande do Sul, Brasi

Ana Gruszynski, Universidade Federal do Rio Grande do Sul, Brasi

Arthur Ituassu, Pontifícia Universidade Católica do Rio de Janeiro, Brasil

Claudia Lahni, Universidade Federal de Juiz de Fora, Brasil

Francisco Paulo Jamil Marques, Universidade Federal do Ceará, Brasil

Jiani Bonin, Universidade do Vale do Rio dos Sinos, Brasil

José Luiz Braga, Universidade do Vale do Rio dos Sinos, Brasil

Leonel Aguiar, Pontifícia Universidade Católica do Rio de Janeiro, Brasil

Luciana Panke, Universidade Federal do Paraná, Brasil

Marcelo Kischinhevsky, Universidade do Estado do Rio de Janeiro, Brasil

Raquel Paiva, Universidade Federal do Rio de Janeiro, Brasil

Sandra Rubia da Silva, Universidade Federal de Santa Maria, Brasil

EDIČ̃̃ DE TEXTO E RESUMOS I Susane Barros

SECRETÁRIA EXECUTIVA I Juliana Depiné

EDITORAÇ̃̃o ELETRÔNICA I Roka Estúdio

TRADUÇÃO I Sieni Campos
COMPós I www.compos.org.br

Associação Nacional dos Programas de Pós-Graduação em Comunicação

Presidente

Eduardo Morettin

Universidade de São Paulo, Brasil

eduardomorettin@usp.br

Vice-presidente

Inês Vitorino

Universidade Federal do Ceará, Brasil

ines@ufc.br

Secretária-Geral

Gislene da Silva

Universidade Federal de Santa Catarina, Brasil

gislenedasilva@gmail.com 